\section{A CASE OF}

\section{I.A'T'E SYPHILITIC GLOSSI'TS TREATED BY SALVARSAN (EHRLICH-HATA).}

\author{
[With Coloured Plate.]
}

BY SIR MALCOLM MORRIS, K.C.V.O.,

CONSULTING SORGEON, SKIN DEPARTMENT, ST. MARY'S HOSPITAL; ON DERMATOLOGY, LONDON

In the case of severe late syphilitic glossitis reported below I was fortunate enough to obtain an excellent drawing in colour of the tongue immediately before treatment by salvarsan, as well as others depicting the condition on the ninth, nineteenth, and fortieth days after treatment. On this account, and also because the case is a striking example of rapid improvement effected by a single dose of salvarsan in a condition which had proved refractory to the regular and protracted exhibition of mercury, it appears to me to deserve publication.

The patient, a male aged 40, had a chancre on the penis, with buboes, in February, 1902, and later in 1902 there was a secondary eruption on the face. In August, 1904, an ulcer appeared on the inside of the lower lip. About a month later lesions on the tongue were noticed, the tongue beginning to swell and to become fissured. From that time until the autumn of 1911, with occasional abatements, the glossitis got giadually worse, the tongue becoming more swollen and the fissures deeper; in October, 1911, it began to split at the tip. All this time the patient had been taking small doses of hydrargyrum cum creta.

When the patient came to me, on November 1st, 1911, the tongue was eroded and painful, and its surface irregular and lobuiated. It was so swollen that it could only be protruded with difficulty, and the teeth could not be seen. There were deep fissures, and at the tip it was split completely through. Ulcers were present both on the tongue and on the lower lip. The Wassermann. reaction was positive. On November 18th 0.6 gram of salvarsan was injected intravenously by Dr. Henry MacCormac, the saline being made from water distilled twenty-four hours before use. There was very little general reaction on the day of the injection, but there was marked swelling of the lower lip. . On the second day the patient felt very sick and uncomfortable, and his temperature was $102^{\circ} \mathbf{F}$., but it fell to normal in the evening and remained so. On the tenth day after the injection the tongue was less swollen and not so painful; by the twelfth day the ulcers had disappeared. During Lecember the fissures began to lieal, those at the base in the direction of the tip, the cleft at the tip in the direction of the base. By January 15th, 1912, the fissures were entirely healed and the tongue had returned to its normal size. The erosions also healed; there is now no soreness, and the patient is able to eat with comfort. An eruption on the scrotum and perineum which had persisted for four or five years, and a slight lesion on the left hand, have entirely disappeared, and the general physical condition has greatly improved. The patient is now taking small doses of mercury by the mouth.

\section{Remaris.}

I know of no other remedy, or combination of other remedies, which is capable of producing so rapid a dis appearance of severe and long-standing lesions as was brought about by salvarsan in this instance. The case appears to me to be worth consideration at a time when there are some signs of a reaction against the new specific. At first, in some quarters, its claims were admittedly put too high. In some cases marked improvement is followed by relapse; in others, though not in many, the disease shows itself obdurate to the remedy; in yet others it has evoked unfavourable symptoms. That such experiences should cause a backward swing of the pendulum was only to be expected. The phases through which tuberculin has passed furnish a warning against the folly of extremes. In that instance the disappointment of exaggerated expectations produced a reaction which led to the undeserved neglect of a valuable agent, and it is only now that tuberculin is finding its true place in the diagnosis and treatment of tuberculosis. That salvarsan is an infallible specific, or that it should be employed promiscuously in syphilis, no one will now maintain. For cases in which there are certain complications or sequelae, such as advanced pulmonary tuberculosis, severe diabetes, grave disease of the liver and kidneys and other abdominal viscera, liability to haemorrhage, pronounced cardio-vascular change, or lesions of the central nervous system, its unsuitability is admitted. In some of these conditions it is doubtless defective elinination, owing to disease of the eliminating organs, that explains the unfavourable results; and the fact that when injected intravenously salvarsan is excreted in the urine much more rapidly than when injected intramuscularly or subcutaneously, is one of the reasons why the first of these methods is preferable to the other. Further advantage of the intravenous methods is the absence, as in the present case, of severe local pain, of infiltration at the site of the injection, and of sloughing of the skin. The general reaction, too, is usually less severe, and seldom lasts longer than the twenty-four hours to which it was limited in this instance.

The case also illustrates the greater amenability to salvarsan of tertiary than of secondary syphilis. It is in the secondary rather than in the tertiary stage that the disease sometimes fails to respond to the remedy. It will be noticed that the striking results described were produced by a relatively small quantity of salvarsan. Some of those who have had most experience with salvarsan have given 1.5 or 1.8 grams, in three fractions distributed over a period of several weeks ; and in treating cases in the secondary period, free from any counter-indications, a more vigorous use of the remedy than was necessary in this case would no doubt be desirable. Bat in respect of dosage, it is too early yet to lay down any rigid rule. It is still necessary to feel one's way cautiously. The reports that have recently been published of fatalities following the administration of salvarsan form, it is true, but an infinitesimal proportion of the great multitude of cases in which it has been employed with safety and with marked benefit. They do not justify the neglect of a potent remedy because it is not entirely devoid of risk, but they do suggest the necessity for caution. It is well to be reminded that heroic measures might easily end in disaster. From one danger, however, which was not unreasonably apprehended as the result of experience with atoxyl-that of damage to the optic nerve-salvarsan appears to be free. Elirlich, in his Experimental Chemotherapy of Spirillosis, states that not a single case of blindness in connexion with salvarsan has been reported to him, and declares that after penetrating research he has been unable to run a single one of these rumoured cases to earth. Wechselmann, who has maintained towards salvarsan a judicial attitude which has not been observed by all who have extensively used it, has testified that in upwards of 1,200 cases in which he had used it at the time of writing, he was unable to find any trace whatever of injury to the optic nerve. In the few cases in which other syphilologists have reported optic nerve changes it is, of course, possible that the disease rather than the remedy was responsible for the mischief.

In supplementing salvarsan with mercury I am following the plan which has all along commended itself to me. Leredde argues brilliantly against the combination, although it has received the imprimatur of Ehrlich himself, and is supported by the high anthority of Neisser. To Leredde's contention that, in practice, the association of the two specifics will end in the ineffective use of both, I am unable to subscribe. At present we know too little of the precise mode of operation of either mercury or salvarsan to be justified in asserting that they have no complementary action. On the other hand, it is obviously true that by combining the remedies they can both be employed well within the margin of safety. When by lapse of time it has been proved that the effects of salvarsan are permanent, we shall be justified, in suitable cases, in relying upon it alone. Until then the prudent course, in my judgement, is to follow it up with moderate doses of mercury. The further treatment, if any be required, must be determined by the course each case runs, and the result of further applications of the Wassermann test. 

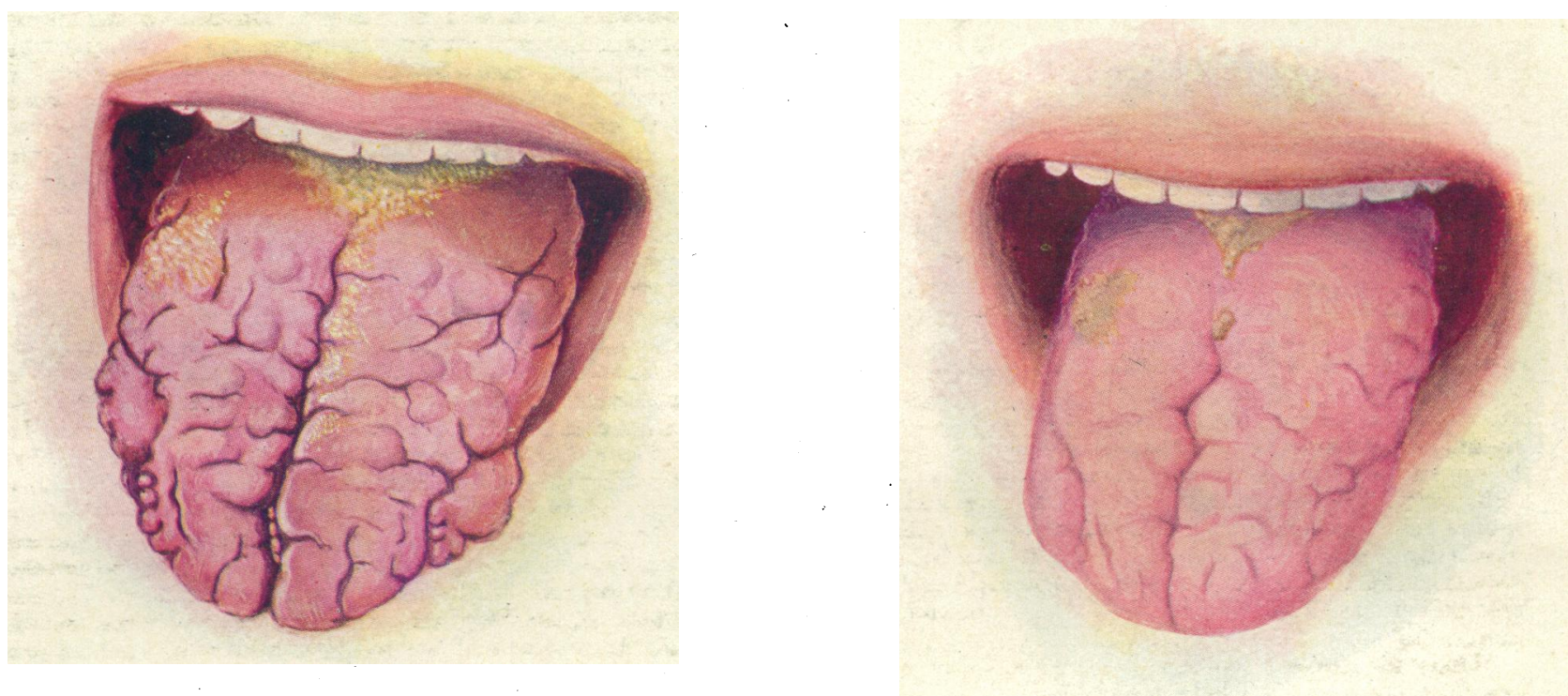

FIG. 1.-CONDITION BEFORE INJECTION.

Fig. 2.-Ninth Day after InJection.
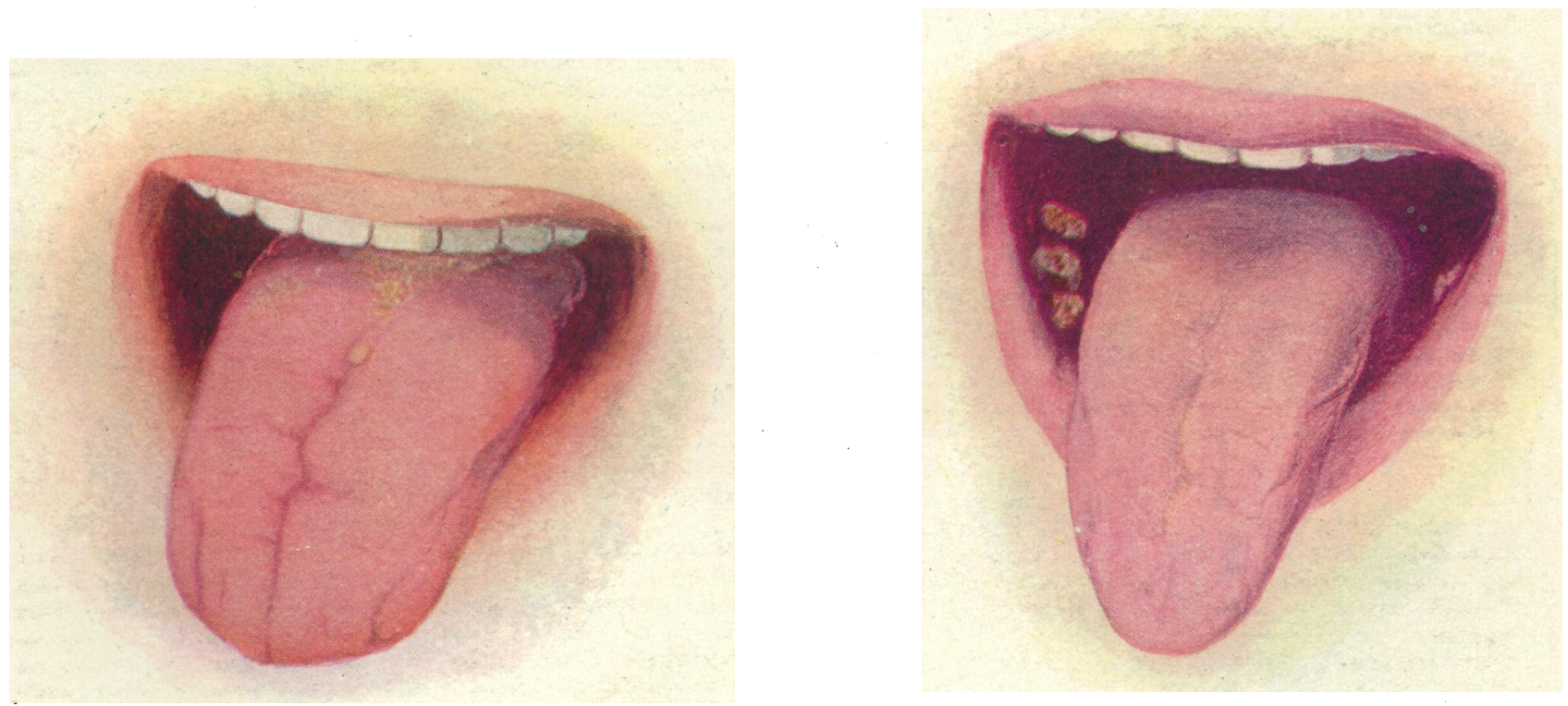

Fig. 3.-Nineteenth Day after In.jection. 